\title{
AUTORIZACIÓN: ACTOS DE HABLA E INTERPRETACIÓN JURÍDICA
}

\author{
José Luis Cifuentes HonRubia \\ Universidad de Alicante \\ Cifu@ua.es
}

\begin{abstract}
Resumen
En este artículo reflexionamos sobre la noción de interpretación en textos legales y su repercusión en la hermenéutica jurídica a partir del artículo 3 del Código Civil. Tras poner de relieve la trascendencia de la noción de interpretación lingüística, y su inadecuada comprensión en derecho, ejercitamos la relevancia de la misma en una aplicación práctica de la interpretación lingüística de los artículos 34.4 y 37.4 de la Ley Orgánica de Reforma Universitaria, a partir de la sentencia número 1151 de 20 de noviembre de 2006, dictada por la Sección Segunda de la Sala de lo ContenciosoAdministrativo del Tribunal Superior de Justicia de la Comunidad Valenciana.

PALABRAS CLAVE: análisis del discurso, interpretación, lingüística forense.
\end{abstract}

\begin{abstract}
This paper focuses on the concept of interpretation of legal texts and its impact on legal hermeneutics regarding Section No. 3 of the Spanish Civil Code. After emphasizing the importance of the concept of linguistic interpretation and its inadequate understanding in law, we consider its relevance when implementing articles 34.4 and 37.4 of Spanish University Reform Act, pursuant to Judgement No. 1151 (20 ${ }^{\text {th }}$ November 2001) delivered by the $2^{\text {nd }}$ Division of the Court for AdministrativeContentious Issues of the High Court of the Autonomous Community of Valencia.
\end{abstract}

KEY WORDS: discourse analysis, interpretation, forensic linguistics.

\section{Introducción}

La Lingüística Forense se define, de forma general, como un punto de encuentro entre lingüística y derecho. Esta disciplina lingüística incluye toda una serie de áreas de investigación y estudio que están relacionadas con el lenguaje administrativo, jurídico y judicial, por un lado, y el uso forense de la prueba pericial lingüística en distintos ámbitos. En este sentido, una de las grandes áreas de actuación de la lingüística forense es el lenguaje jurídico y legal. Son muchos los aspectos que integran el estudio del lenguaje jurídico y legal, y no cabe duda de que uno de ellos es el peritaje sobre determinados textos oficiales para resolver posibles ambigüedades, 
o dudas, en la interpretación ${ }^{1}$. El trabajo que presentamos se inscribe en esta línea de trabajo, es decir, se trata de un análisis discursivo sobre un texto legal.

\section{Interpretación lingüística e interpretación jurídica}

El artículo 3 del Código civil propicia una necesaria colaboración entre lingüística y derecho:

Las normas se interpretarán según el sentido propio de sus palabras, en relación con el contexto, los antecedentes históricos y legislativos y la realidad social del tiempo en que han de ser aplicadas, atendiendo fundamentalmente al espíritu y finalidad de aquéllas.

Este primer párrafo del artículo 3 del Código civil parece ser uno de los textos más citados por la jurisprudencia del Tribunal Supremo y parece constituir (Salvador Coderch, 2001: 516) una de las innovaciones más notables de las introducidas por el Decreto 1.836/1974, de 31 de mayo, por el que se sancionaba el Título Preliminar del Código civil, siendo el primer intento de regulación de la interpretación en el Código civil español y, en los 35 años de vigencia, ha sido muy utilizado para proponer y justificar determinadas soluciones interpretativas.

En derecho parece ser común la distinción entre interpretación lingüística, interpretación doctrinal e interpretación usual (Salvador Coderch, 2001: 517 y ss.). Por interpretación lingüística suele entenderse una noción de significado valorable en términos de verdad o falsedad (Hernández Marín, 1989: 245-267), aunque también consideran que el sentido de la interpretación dependerá tanto de lo dicho lingüísticamente como del contexto, lingüístico y no lingüístico, en que viene dado el texto en cuestión (Hernández Marín, 1989: 249-250).

No obstante lo anterior, la consideración de interpretación doctrinal sólo podría entenderse valorando la interpretación lingüística en el sentido primero dado, es decir, considerada en términos de verdad o falsedad, pues suele entenderse en derecho que interpretar una ley consiste en explicar su sentido frente a un caso concreto, es decir, el resultado práctico del mensaje que contiene, y el objetivo de la interpretación es la averiguación del sentido o espíritu del precepto (Albaladejo, 1989: 155; Díez-Picazo, 1980: 724), por lo que se concibe, en realidad, la interpretación lingüística como una simple descripción de la realidad, sujeta, por ello, a los dictados de la lógica veritativa, mientras que la interpretación doctrinal se considera tanto o más valorativa o normativa que descriptiva, y diferente de otros modos de razonar

1 El Prof. Alcaraz (2005: 50) señalaba, a propósito del uso del lenguaje jurídico, que quizás las dos vías de análisis del mismo más valoradas serían la identificación de la autoría de los textos, y la determinación del significado de las palabras, las oraciones y los enunciados textuales. 
científicos naturales o sociales ${ }^{2}$. Es claro que una consideración tal de interpretación obvia toda la consideración que, en linguística, se tiene de la noción de contexto.

La noción de interpretación usual es distinta, pues viene referida a la aplicación judicial del derecho, es decir, se trata de dictar la resolución judicial correspondiente en cumplimiento de la ley de que se trate. Para los juristas, el esquema cognitivo de la aplicación de la ley requiere una interpretación lingüística previa, a la que luego se le añaden los medios y recursos interpretativos específicos del derecho y que tienen como consecuencia la interpretación doctrinal (De Castro, 1984: 462).

A pesar de todo, se reconoce que la interpretación lingüística es el punto de partida para la corrección de la actividad judicial en términos de verdad o falsedad (pues recordemos que se considera el significado lingüístico en términos de verdadero o falso) (Salvador Coderch, 2001: 518), pero sólo el punto de partida, pues el sentido literal o gramatical y el sentido de la interpretación doctrinal, en el que confluye el "espíritu, finalidad o razón" de la ley son diferentes, como ya hemos dicho anteriormente, por lo que la interpretación gramatical se considera insuficiente, requiriéndose en todos los casos una interpretación jurídica "conforme a su fin" (De Castro, 1984: 467-468).

Desde el punto de vista de la lingüística, las disquisiciones anteriores sobre la noción de "interpretación" carecen de sentido, pues la interpretación lingüística no es la interpretación veritativa. De igual forma, desde el punto de vista lingüístico, la diferenciación entre interpretación lingüística e interpretación doctrinal sólo tendría sentido en la medida en que se equipararan a las nociones de "significado" y "sentido" (o "uso"). Es más, a poco que analicemos el artículo 3 del Código civil, nos daremos cuenta de que se está proponiendo una interpretación basada en el "uso", pues las normas se deben interpretar según su contexto: lingüístico, histórico, legislativo, social, y considerando el hacer de los sujetos discursivos en la interpretación de las normas (en tanto discursos), y unos sujetos que, evidentemente, deben estar modalizados con un saber sobre aquello que hacen, lo cual quizás explica la afirmación de Culthard (2005: 250) de que los abogados y los jueces normalmente se ven a sí mismos como los custodiadores del significado de los textos legales. No obstante, la práctica de la lingüística forense pone de manifiesto su utilidad en la interpretación textual, pues, como Alcaraz y Hughes señalaban (2002: 56), las trabas más importantes que encuentran los jueces, y los demás operadores jurídicos, en la interpretación de los enunciados son dos: la imprecisión léxica y la ambigüedad sintáctica.

\subsection{Teoría pragmática del significado}

La tesis del significado como uso parte de la crítica de Wittgenstein a la semántica de condiciones de verdad. La consideración de Wittgenstein de la plura-

2 Una peculiaridad del derecho es que la argumentación jurídica incrementa la realidad también jurídica. 
lidad de usos posibles del lenguaje hace que la función representativa pierda su posición privilegiada, pues el lenguaje no sirve meramente para describir hechos, junto a esas acciones se sitúan otras como dar órdenes, prometer, saludar, etc., es decir, Wittgenstein descubre el carácter de acción de las expresiones lingüísticas ${ }^{3}$. Wittgenstein considera que el lenguaje tiene sentido, no porque se refiera a cosas o porque sea lógicamente coherente, sino porque es un instrumento de comunicación. La lengua no sirve para transmitir un saber dado que le sería exterior, es parte constituyente de ese saber. No es una descripción de hechos, sino un medio de coordinar los actos de varios sujetos operantes. Ya no se tratará de mostrar la forma lógica, sino la estructura de los usos concretos del lenguaje: toda expresión tiene múltiples usos en función del contexto en que se utilice, variando su sentido en cada caso; esta tesis supone el abandono de la idea de una estructura lógica homogénea para toda la realidad y el lenguaje; la estructura del lenguaje no se puede obtener a partir de una teoría lógica abstracta, sino a través de una investigación antropológica del uso que hacemos del lenguaje, del lenguaje cotidiano. El sentido se define, pues, por el uso, en tanto que el lenguaje es puesto en correspondencia con unas situaciones. Concluye Wittgenstein que la ambigüedad entre dos enunciados es levantada no por una diferencia entre los significantes, sino por la situación en que son empleados. La significación así concebida no es siempre absolutamente unívoca, se la podría definir como lo que es comprendido en medio de tal situación sociocultural. El signo es inerte, sólo el uso le da vida, dice Wittgenstein. La lengua no sólo viene usada para la descripción del mundo, sino también en acciones lingüísticas, en "juegos de habla", que son introducidos en una forma de vida. El lenguaje se aprende, pues, actuando, aprendiendo las reglas sociales del lenguaje, aprendiendo los distintos juegos del lenguaje; cada juego tiene sus reglas propias en función de las formas de vida en las que se usan, conduciendo a distintos tipos de conducta.

El juego en que los actos de habla prestan soporte a la práctica interactiva es de un modo muy distinto al prestado antes por las actividades coordinadas previas. La emisión de un acto de habla entraña al mismo tiempo la comunicación del tipo de acción que el hablante está llevando a cabo, y el oyente puede identificar el acto de habla como la realización de una determinada acción. Esta estructura reflexiva del lenguaje vincula el contenido proposicional comunicado con un compromiso del hablante, con la manera en que cuenta su acto de habla. De esta manera, el significado pragmático del habla se explica en términos de un conjunto de dimensiones de validez, que han de verse como pretensiones de reconocimiento intersubjetivo.

3 Más tarde, Austin, a partir de los verbos realizativos explícitos, intentó sistematizar y ordenar los posibles usos del lenguaje dentro de unos pocos modos de empleo básicos. Ello le permitió analizar el doble rendimiento de los actos de habla: por medio de ellos el hablante, al tiempo que dice algo, hace algo con palabras. 
La lengua no es una simple y mera transmisión de información: cuando el hombre usa el lenguaje para establecer una relación consigo mismo o con sus semejantes, el lenguaje no es simplemente un instrumento, un medio, es una manifestación del ser íntimo y del vínculo psíquico que nos une al mundo y a nuestros semejantes. Ese "algo más" de la lengua es lo que nos hace considerarla como un juego, o más exactamente como las reglas de un juego, y de un juego que se confunde normalmente con la existencia cotidiana. El uso de la lengua no sólo es un acto específico, sino una parte integral de la interacción social.

El juego lingüístico da una especial relevancia al hecho de que el uso lingüístico se atiene a reglas específicas según los distintos contextos vitales, que a distintos juegos lingüísticos corresponden distintos sistemas de reglas. La regularidad del uso lingüístico es un supuesto para la intercomunicación mediante el lenguaje, sin reglas para el empleo no podrá haber tampoco un significado fijo. Los juegos lingüísticos son maneras particulares, reales o imaginarias, de usar el lenguaje, que tienden a mostrar cuáles son las reglas de un uso lingüístico. Sin embargo, no hay un número infinito e indefinido de juegos lingüísticos o usos del lenguaje.

Así pues, en la mayor parte de los casos en los que hablamos del significado de las palabras, éste puede explicarse hablando del uso que hacemos de ellas. El uso de las palabras en el lenguaje, en los juegos lingüísticos, está sometido a reglas; es la conexión regular entre los sonidos y las acciones lo que testimonia la existencia de un lenguaje. Son las reglas, por su parte, las que nos permiten hablar de corrección e incorrección en el uso del lenguaje, y las que nos permiten prever el comportamiento lingüístico de los demás.

Así pues, parece ir dibujándose una concepción del discurso como práctica entre otras prácticas, lo cual supone una incidencia no ya en lo que el discurso dice o manifiesta, sino en lo que hace al decir. Lo específico del hacer semiótico no es ya la aplicación de una teoría de los signos, sino el examen de la significación como proceso que se realiza en textos donde emergen e interactúan sujetos, y sujetos con unas intenciones comunicativas determinadas.

\section{Análisis discursivo}

Nos proponemos como objeto de estudio la Sentencia $n^{\circ}$ 1151/2006 de la Sección Segunda de la Sala de lo Contenioso-Administrativo del Tribunal Superior de Justicia de la Comunidad Valenciana. En dicha sentencia se trata la provisión de una plaza de Profesor Titular de Escuela Universitaria reclamada por uno de los actores concursantes. El demandante, que no fue propuesto por la Comisión de Selección ni por la Comisión de Reclamaciones de la Universidad que ofertaba la plaza, recurrió dicha provisión sustentando su argumentación en que la persona demandada (que fue la propuesta por la Universidad), no reunía todos los requisitos necesarios para participar en el concurso, lo que debería haber determinado su exclusión, y 
ello basándose en el artículo 37.4 de la Ley Orgánica 11/1983 de 25 de agosto de Reforma Universitaria, a cuyo tenor se dice:

No podrán concursar a plazas de Profesor Titular de Universidad quienes hubieran estado contratados durante más de dos años como ayudante en la Universidad a la que corresponda dicha plaza. Quedan exceptuados de esta exigencia quienes durante un año o más hubieran realizado tareas de investigación o hubieran sido ayudantes en otra u otras Universidades españolas o extranjeras, o hubieran estado en la situación prevista en el apartado 4 del artículo 34.

El apartado 4 del artículo 34 dice lo siguiente:

Los ayudantes a que alude el apartado anterior, cuando realicen estudios en otra Universidad o institución académica, española o extranjera, autorizados por la Universidad en la que estén contratados, podrán seguir manteniendo su condición en los términos y en el plazo máximo que fijen los respectivos Estatutos, que no podrán superar lo establecido en el apartado anterior de este artículo.

El argumento propuesto por el demandante con el fin de solicitar la anulación de la provisión de la plaza y volver a celebrar el concurso con el demandante como único concursante, es el siguiente:

La candidata propuesta, en la fecha de la Convocatoria (22 de noviembre de 2001), llevaba más de dos años contratada como Profesora Ayudante de la Universidad de ... ${ }^{4}$ - concretamente desde el 21 de octubre de 1999 hasta el 31 de agosto de 2002 - por lo que, en principio, no podía aspirar a la plaza de titular, salvo que se acogiera a la excepción prevista en la normativa a la que hemos hecho referencia. Lo hizo y tanto la Comisión calificadora del concurso, como posteriormente la de Reclamaciones, entendieron que cumplía, por estar comprendida en el artículo 37.3 en relación con el 34.4 de la Ley Orgánica 11/1983, los requisitos exigidos para concursar toda vez que de marzo a septiembre durante los años 1997, 1998 y 1999, de julio a octubre durante los años 2000 y 2001 y de julio a septiembre durante el año 2002 realizó tareas de investigación en el Seminario Diocesano ..., Centro de Estudios Superiores afiliado como Seminario Mayor de ... a la Facultad de Teología ... El recurrente disiente de ello afirmando que, aparte de que la codemandada no alegó ni acreditó la concurrencia de dicha excepción en el momento de su participación en el concurso - como imponía la Base $4^{\text {a }}$ de la Convocatoria-, las tareas de investigación que realizó en el Seminario Diocesano de... carecían de relevancia a efectos de generar la excepción prevista en el artículo 37.4 en relación con el 34.4 LORE por las siguientes razones: a) Porque el citado Seminario no es, como exige la norma, una Universidad; b) Porque

4 Omitiremos algunos datos con el fin de no difundir de manera relevante la identidad de los implicados. 
no se indican con exactitud los períodos en que se realizaron dichas tareas ni el contenido de las mismas; y c) Porque no consta acreditado que en su momento la Universidad de ... concediera autorización para realizarlas.

El tribunal, finalmente, aceptará los argumentos del demandante, aunque rechaza el argumento a), pues considera probado que el Seminario Diocesano ... es institución académica de rango universitario según los acuerdos entre el Estado Español y la Santa Sede sobre enseñanzas y asuntos culturales de 3 de enero de 1979 (BOE de 15 de diciembre de 1979), y concluye, por ello, que las tareas de investigación realizadas en dicho Seminario por la demandada pueden integrar los estudios a que se refiere el artículo 34.4 LORE. La fundamentación del fallo a favor del demandante viene dada por el argumento marcado como c), no considerando el b) ya que si no está acreditada la autorización para el período de investigación, no tiene relevancia la exactitud de las fechas del mismo:

... debe considerarse que no consta que, tal como exige el citado artículo, la Universidad de ... le concediese, durante el período en que aquélla desarrolló las citadas tareas de investigación teniendo la condición de Profesor Ayudante de dicha Universidad, para ello la autorización a que se refiere la citada norma a efectos de mantener dicha condición de Profesora Ayudante. Y al faltar dicho requisito - que es presupuesto ineludible para entender aplicable la excepción prevista en el artículo 37.4 en relación 34.4 LORE - debe concluirse que Doña ... no reunía los requisitos exigidos para participar en el proceso selectivo de que se trata, lo que justifica la anulación de los actos en virtud de los que se produjo y ratificó, tras la superación de aquél, la propuesta a su favor para la provisión de la plaza ... del Área de Conocimiento ..., de Profesor Titular de Escuela Universitaria.

Así pues, debemos concluir que el Tribunal estima que debe repetirse el concurso de la plaza sin la presencia de la candidata demandada, que fue quien la ocupó a propuesta de la Comisión, y actuando como único concursante el demandante recurrente. Y la razón fundamental que utiliza el Tribunal para tal fallo viene dada porque la Universidad de la demandada no autorizó a la misma para realizar las estancias de investigación (que sí parece que hizo, aunque no se consideraron por no estar autorizadas) en el Seminario Diocesano. Como vemos por lo expuesto, el argumento crucial de la sentencia es la falta de autorización hacia la demandada por parte de la Universidad, es decir, el incumplimiento del artículo 34.4 de la LORE en el que se señala expresamente que debe haber autorización por parte de la Universidad del Ayudante para que, en caso de estancia investigadora en otro centro, dicha estancia sea entendida como excepción permitida al artículo 37.4. Lingüísticamente es muy interesante este aspecto porque, claro, autorizar es un tipo de acto de habla muy interesante. 


\subsection{Actos de habla}

En el análisis de las lenguas, un "acto de habla" es la emisión de un enunciado en un contexto dado para llevar a cabo los fines de la interacción comunicativa, tales como solicitar información, pedir disculpas, ordenar, expresar nuestro estado de ánimo, etc. Todos ellos son actos realizados en el proceso de hablar. Pero cuando nosotros hablamos de "actos de habla" nos vamos a referir al acto de habla que puede entenderse como un aspecto de la interacción social. Un acto de habla viene dado cuando el enunciador $\mathrm{E}$ realiza una enunciación $\mathrm{N}$ para el enunciatario $\mathrm{R}$ en un contexto C. Los actos de habla son parte del comportamiento social interactivo y deben ser interpretados como un aspecto de la interacción social. Adaptando las palabras de Habermas (1987: 2), el enunciador enuncia algo comprensiblemente, da al enunciatario algo para comprender, se hace por ello comprensible, y entra en comprensión con otra persona. Habermas señala otros condicionantes para el enunciador E: debe creer la verdad de lo que dice, de forma que el enunciatario pueda compartir el conocimiento de $\mathrm{E}$; debe expresar sus intenciones de tal manera que la expresión lingüística represente lo que se entiende (de forma que R pueda confiar en E); debe realizar el acto de habla de manera que sea conforme a las normas reconocidas o aceptadas.

La interacción social no debe entenderse como algo externo al lenguaje. El lenguaje inscribe en su propia naturaleza las coordenadas del mundo intersubjetivo, orientando, regulando y transformando los modos de correspondencia entre los sujetos, además de servir a la objetivación de las distintas experiencias de la realidad. El lenguaje produce relaciones intersubjetivas y es, al mismo tiempo, su producto.

La teoría de los actos de habla se basa en la idea de que siempre que emitimos un enunciado estamos realizando acciones o cosas por medio de palabras, y fue concebida para demostrar la llamada "falacia descriptiva", mediante la cual una oración no siempre tiene que ser verdadera o falsa, ni se usa siempre para describir un hecho o un estado de cosas:

\section{Bautizo a este barco con el nombre de Libertad \\ Lo lamento \\ Te felicito \\ Te ordeno que lo hagas \\ Te autorizo a que hagas $X$}

Al enunciar todos los enunciados anteriores bajo las condiciones correctas, el hablante realiza, respectivamente, un acto de nombrar, un acto de lamentar, un acto de felicitar, un acto de ordenar, y un acto de autorizar, por lo que, en los anteriores ejemplos, su enunciación es la realización de una acción. Al enunciar uno cualquiera de los enunciados anteriores, el hablante no sólo está simplemente registrando un estado de cosas, transmitiendo una información, o describiendo una acción: la está haciendo. Por ejemplo, cuando uno dice lo lamento, no está pretendiendo sim- 
plemente informar a su interlocutor de algo que ignora, realmente está realizando la acción de lamentar. Los actos de habla se usan para llevar a cabo distintos tipos de acciones, más o menos ritualizadas o convencionalizadas, uno de cuyos pasos puede consistir en pronunciar determinadas palabras.

Una propiedad característica de los actos de habla es la autorreferencia o reflexividad, es decir, significan reflexivamente su valor de actos porque se presentan al mismo tiempo que representan. Así, la oración Afirmo que Castro es el azote del imperialismo yanqui, remite representativamente, en tanto que significa, a las entidades Castro, azote e imperialismo yanqui, pero también se presenta simultáneamente como un acto de afirmación por parte del hablante, siendo el sentido de la enunciación el logro simultáneo del significado del enunciado y del sentido del acto.

Además de tener propiedades externas diferenciadas, los actos de habla poseen también condiciones especiales de emisión: las palabras tienen que decirse en las circunstancias apropiadas. Si fallan las convenciones que regulan el cumplimiento de dichas acciones, la emisión y el acto realizado pueden fracasar. Por ejemplo, en el caso de lo lamento, se espera que quien emite esa enunciación realmente tenga ese sentimiento, pero, si no es así, no podemos decir que el enunciado sea exactamente falso, sino que fue una expresión insincera, que no se dijo albergando los sentimientos requeridos. Lo mismo ocurre si el que ordena no es la persona con potestad reconocida para hacerlo (un hijo a su padre, por ejemplo, o un soldado a un capitán).

\subsection{Actos de habla indirectos}

Los actos de habla pueden ser "directos" e "indirectos". Son actos de habla directos aquellos en los que se emplea un verbo que explicite la fuerza intencional del acto de habla:

Te ruego que te levantes

Te sugiero que te vayas

Te autorizo a entrar

Pero la realidad es que la mayoría de los actos de habla se llevan a cabo de forma indirecta, por medio de lo que se llama "actos de habla indirectos". No siempre hay una correspondencia entre el tipo de oración y el tipo de acto de habla. No todas las oraciones interrogativas se usan para preguntar, ni todos los imperativos realizan el acto de mandar, ni todas las oraciones aseverativas tienen la fuerza de aserciones. Hay muchos usos en los que el hablante quiere dice algo ligeramente distinto de lo que realmente expresa: estos usos se denominan actos de habla indirectos. La entonación, la expresión facial, los gestos, la distancia, la postura de los interlocutores, el contexto en general, tienen una importancia extrema para el logro indirecto de actos de habla. La definición discursiva e interaccional de los actos de habla conlleva el reconocimiento de que cualquier acto de habla es analizable como acto indirecto 
dentro del discurso: las formas lingüísticas seleccionadas por el hablante cuentan sólo como una de las indicaciones que el oyente toma en cuenta en su interpretación de la expresión del hablante, y es, en última instancia, la actividad interpretativa del hablante la que consuma el logro de un acto y su consiguiente definición como tal tipo de acto intencional.

Así, un ejemplo como ¿puede pasarme la sal?, dicho por un comensal a otro comensal en el transcurso de una comida, difícilmente se entendería como una pregunta a la que, por tanto, se puede contestar con un sí o no, sino que debe entenderse, evidentemente, como una petición no explícita. Es decir, en nuestra comunidad de habla no tenemos por qué emitir un enunciado como te pido que me pases la sal para hacer una petición, es decir, no tenemos por qué utilizar un verbo explícito (pedir) para lograr determinado acto (petición), sino que, por una convención social en este caso (y por el contexto siempre), es posible utilizar otros medios para la realización de dicho logro. De igual forma, en ciertos contextos, un enunciado como ¿has sacado el perro a pasear?, dicho por un padre a su hijo, no siempre tiene que interpretarse como una pregunta, sino que, en ocasiones y según determinadas circunstancias contextuales, puede entenderse como una orden o una recriminación, aunque no esté explícito ningún verbo como te ordeno o te recrimino.

En el siguiente ejemplo podemos encontrarnos ante 24 formas de expresar lo mismo (una demanda o mandato) mediante 24 actos de habla diferentes. Sin embargo, sólo 6 de esas expresiones pueden considerarse actos directos, son los 6 enunciados que o bien contienen el verbo pedir/ordenar en primera persona del singular (1), o bien contienen el verbo cerrar en imperativo $(2,3,18,19 \text { y } 23)^{5}$ :

(1) Te ordenolte pido que cierres la puerta.

(2) Cierra la puerta.

(3) ¿Cierra la puerta, ostras!

(4) ¿Podrías cerrar la puerta?

(5) ¿Te importaría cerrar la puerta?

(6) ¿Eres de Madrid?

(7) Se va a escapar el gato.

(8) Hace frío, ¿eh?

(9) Por favor, ¿sería tan amable, si no le importa, de cerrar la puerta?

(10) ¿Es que eres incapaz de cerrar la puerta?

(11) Qué corriente, ¿no?

(12) ¿Puedes cerrar la puerta?

(13) ¿Quieres cerrar la puerta?

(14) ¿Quieres hacer el favor de cerrar esa puerta?

(15) ¿Es que no has visto el cartel o qué?

(16) Te has dejado la puerta abierta.

(17) ¿Esperas a alguien?

5 Ejemplo tomado de Casalmiglia y Tusón (1999: 198-199). 
(18) Oye, cierra la puerta.

(19) ¡La puerta, ciérrala ya de una vez!

(20) ¿Cerrarás la puerta?

(21) ¿Y si cerráramos esa puerta?

(22) ¿Has nacido en un circo?

(23) Cierre con cuidado.

(24) i'Sa puerta!

Los 18 enunciados restantes son actos de habla indirectos, que tienen diferentes grados de convencionalidad. En siete de ellos (6, 7, 8, 11, 15, 17 y 22) no aparecen ni cerrar ni puerta, por lo que para su interpretación necesariamente se requerirá recurrir a aspectos contextuales como el conocimiento mutuo o elementos del entorno (temperatura, carteles, etc.), es decir, el enunciatario requerirá un refuerzo contextual para completar la información del emisor. En los 11 restantes, sí aparecen elementos léxicos como cerrar y puerta (los dos o uno sólo) que orientan para la interpretación apropiada de las intenciones de quien emite esas expresiones, aunque estén estructuradas de forma indirecta.

Un último ejemplo, en este caso obtenido de una sentencia judicial: la importancia del contexto en el tipo de acto de habla que se realiza se refleja en la argumentación de la siguiente sentencia del Tribunal Constitucional sobre la admisión de Herri Batasuna en sus espacios electorales de un comunicado de la organización terrorista ETA, donde se establece que hay una amenaza, aunque no haya habido ningún verbo explícito que indicara tal amenaza:

En el spot televisivo [de Herri Batasuna] conviven también dos mensajes o comunicados. Uno atribuible a H.B. y otro a ETA. En efecto, como se recordará, después de una voz en off de H.B. en la que cede la palabra a ETA, ésta expone sus objetivos políticos y concluye con la afirmación de que "en caso de que se admitieran los puntos que han de convenir con el Estado español (...) ETA anunciaría el alto el fuego". Durante toda la transmisión del mensaje aparecen de forma destacada en un primer plano tres pistolas sobre la mesa y delante de los tres encapuchados que transmiten el mensaje. Al final se pide el voto para H.B.

En estas circunstancias es evidente que de la conjunción del mensaje oral y el visual se desprende una amenaza dirigida a los poderes públicos e indirectamente a los ciudadanos para que acepten los planteamientos políticos expuestos si no quieren continuar sufriendo las consecuencias derivadas de los atentados terroristas. Se trata ciertamente de una amenaza difusa, pero de cuya virtualidad ningún ciudadano medio podía dudar y que afectaba a bienes tan importantes como la vida y la integridad física. Pero este carácter amenazante se ve reforzado al integrarse en el spot electoral de H.B. ya que en este caso ese contenido genéricamente intimidatorio se vincula explícitamente con la petición de voto para H.B. de modo que la impactante presencia de las armas 
revela de forma manifiesta que de no otorgarse el voto a la asociación política la violencia continuará.

(Fundamento jurídico 19b de la Sentencia del Tribunal Constitucional español de 20 de julio de 1999) ${ }^{6}$.

No obstante, los hechos institucionales parecen caracterizarse por la preferencia e inclinación de los hablantes a requerir que sean realizados mediante actos de habla explícitos, ejecutados de acuerdo con reglas estrictas.

\subsection{Tipos de actos de habla}

Es posible hacer diversas clasificaciones de tipos de actos de habla. De todas ellas, la más común es la realizada por John Searle, en ella "autorizar" es un tipo de acto de habla directivo:

\begin{tabular}{|l|l|l|l|}
\hline Austin & Vendler & Searle & Bach y Harnish \\
\hline Expositivos & Expositivos & Asertivos & Asertivos \\
\hline Compromisivos & Compromisivos & Compromisivos & Compromisivos \\
\hline Comportativos & Comportativos & Expresivos & Reconocimientos \\
\hline \multirow{2}{*}{ Ejercitativos } & $\begin{array}{l}\text { Interrogativos } \\
\text { Ejercitativos }\end{array}$ & Directivos & Directivos \\
\hline Veridictivos & Veridictivos & Declaraciones & Veridictivos \\
\cline { 2 - 3 } & Operativos & & Efectivos \\
\hline
\end{tabular}

Un acto de habla directivo viene definido por la intención del hablante de que su interlocutor haga algo, como ocurre con las órdenes, las peticiones o los ruegos. A su vez, Bach y Harnish (1979: 47) organizan los actos de habla directivos en 6 subtipos:

1. Requeridores: pedir, implorar, solicitar.

2. Interrogativos: preguntar, interrogar.

3. Conminativos: ordenar, exigir, demandar.

4. Prohibitivos: prohibir, restringir, vedar.

5. Permisivos: dejar, permitir, autorizar.

6. Admonitivos: Advertir, prevenir, sugerir.

Dentro de cada tipo habría varios grados de fuerza. Así, implorar es más fuerte que solicitar, exigir que requerir, autorizar que permitir, o advertir que prevenir.

Searle determina el carácter regulado y convencional de los actos de habla mediante el concepto de regla constitutiva: una regla es constitutiva respecto a cierta actividad cuando su violación priva a esa actividad de su carácter específico; es

6 Ejemplo tomado de Portolés (2004: 187-188). 
decir, la existencia de la regla crea la posibilidad misma del comportamiento que regula, como ocurre en los juegos. Para Searle, las reglas sintácticas y semánticas que fijan el valor intencional de los enunciados, son constitutivas respecto al empleo de los enunciados. El valorar una enunciación en cuanto determinado acto de habla es una convención, es decir, la realización de una regla constitutiva.

Las cuatro reglas básicas que Searle propone son las siguientes:

1. Regla de contenido proposicional: diferencia el contenido de la expresión del acto. En una advertencia, el contenido proposicional debe basarse en un acontecimiento o estado futuro, para expresar una lamentación, en cambio, el contenido proposicional debe referirse a un acto pasado hecho por el interlocutor.

2. Reglas preparatorias: especifican los supuestos que han de darse por parte de los interlocutores para la realización eficaz del acto; en la promesa se requiere, entre otras, la presunción del hablante de que su interlocutor prefiere que se realice el acto a que no se realice; en una orden es preciso que el hablante tenga algún tipo de autoridad sobre su interlocutor.

3. Regla de sinceridad: el acto se cumple sólo si el hablante intenta seriamente cumplirlo; una expresión resulta desafortunada como acto de promesa si el hablante no trata sinceramente de obligarse.

4. Regla esencial: constitutiva en sentido estricto, determina a las restantes, pero requiere para su aplicación la previa satisfacción de todas ellas. Indica que una enunciación vale por determinado acto de habla, y que el hablante asume las consecuencias sociales de su acción; en la promesa, la expresión cuenta como la adquisición del hablante de la obligación de hacer algo; en una pregunta, la emisión de la enunciación cuenta como un intento de obtener del oyente una información.

En el caso de una autorización, los aspectos fundamentales (en tanto que más problemáticos) consistirían en las reglas preparatorias de la misma, que determinarían la regla esencial ${ }^{7}$. Así, dos reglas preparatorias fundamentales consistirían en 1) el hablante debe estar cualificado para autorizar, 2) el hablante debe saber que su interlocutor puede hacer aquello para lo que le autoriza.

\subsection{Autorización e interpretación}

Supongamos un caso concreto, como es el acto de habla "autorización" inserto en el artículo 34.4 de la Ley Orgánica de Universidades, en el que se recoge que la Universidad autorizará a los Ayudantes a realizar estudios en otra Universidad o

7 La regla de sinceridad, siendo importantísima, es obvia, pues el hablante debe comprometerse en la sinceridad de su autorización. Por otra parte, la regla de contenido proposicional consistiría en un acto futuro a realizar por el interlocutor. 
institución académica española o extranjera. La regla preparatoria 1 nos dice que quien debe autorizar debe estar cualificado para ello, luego parece lógico suponer que quien podrá autorizar a un Ayudante a realizar estudios en otra institución será alguno de los siguientes representantes institucionales de:

a) el Departamento correspondiente,

b) la Facultad a la que esté adscrito,

c) el Rectorado de la Universidad.

La regla preparatoria 2 nos dice, en este caso, que el representante institucional que autoriza al Ayudante a realizar estudios en otra institución sabe que su interlocutor puede hacer aquello para lo que le autoriza; por ejemplo, no se puede autorizar a un Ayudante a ausentarse durante un tiempo de su puesto de trabajo si dicho Ayudante tiene obligaciones docentes que cumplir durante el periodo de estancia en la otra institución, pues ello sería una autorización para un incumplimiento de obligaciones y deberes y, por tanto, motivo de sanción. Es decir, no se puede autorizar para hacer algo ilegal porque, entonces, se atentaría contra la propia autoridad ya que no se tendría autorización para ello. Estas reglas preparatorias, junto con el resto, contribuirían a la conformación de la regla esencial, en este caso un poder hacer por parte del interlocutor motivado por el saber sobre el mismo por parte del hablante (institucional).

El siguiente aspecto que podemos plantearnos es si, en el ejemplo propuesto, es posible un acto de habla indirecto, es decir, un acto de habla en el que el hablante (institucional) no utilice explícitamente el verbo autorizo. La respuesta es, evidentemente, sí, y la fundamentación teórica al respecto está expresa en el apartado 2. Veamos, a continuación, un ejemplo en el que se posibilita, institucionalmente, una autorización como acto de habla indirecto:

Si quien está facultado para autorizar (en el caso que nos ocupa, un Departamento, la Facultad, o el Rectorado) sabe que el interlocutor (el Ayudante, en este caso) puede hacer aquello para lo que se le autoriza, como es una estancia investigadora en otro centro, porque desde los organismos responsables de la docencia se organiza la misma de manera que se concentre la docencia en medio año, dejando el otro medio año libre de docencia, eso, en el contexto universitario supone que la doble actividad del profesorado universitario (Personal Docente e Investigador) en vez de estar simultaneada a lo largo del año, está dividida y concentrada: medio año docencia, medio año investigación. Si quienes organizan la docencia (Departamento y Facultad) y quienes la supervisan (Rectorado) tienen conocimiento de ese hecho es, evidentemente, porque están propiciando y autorizando al interlocutor a hacer lo que puede hacer. Es decir:

a) El Dpto. organiza la docencia, la Facultad la supervisa, y el Rectorado es informado al respecto. Estas funciones están recogidas en diversos reglamentos de funcionamiento administrativo. 
b) El Dpto. organiza la docencia de la Ayudante del ejemplo, y la concentra en un cuatrimestre. La Facultad supervisa esa organización y la admite. El Rectorado es informado y la admite.

c) El Dpto. sabe que la Ayudante no va a ir a la Universidad durante un cuatrimestre. La Facultad también tiene conocimiento de que no va a ir a la Universidad durante un cuatrimestre.

d) La Ayudante sabe que tanto el Dpto. como la Facultad tienen conocimiento de que va a realizar una estancia en otra institución durante un cuatrimestre y que, por ello, no irá a su puesto de trabajo.

e) Tanto el Dpto. como la Facultad no informan al Rectorado de ningún incumplimiento en las funciones laborales de la Ayudante, como hubiera sido la ausencia de su puesto de trabajo durante un cuatrimestre.

f) El Dpto. y la Facultad emiten sendos informes en los que expresan que tenían conocimiento de que la Ayudante utilizaba el periodo laboral en el que no tenía docencia para hacer estancias investigadoras durante una serie de años.

g) El Dpto. y la Facultad han autorizado, de forma implícita, a la Ayudante a hacer las estancias de investigación. El Rectorado de la Universidad asume la autorización de sus instituciones dependientes.

Supongamos otro ejemplo: un padre no permite ver la televisión a su hijo. El hijo sabe que su padre no le permite ver la televisión. Si, en alguna ocasión, el hijo ve la televisión sabiendo que su padre sabe que él está viendo la televisión, será, evidentemente, porque su padre ha hecho una autorización implícita para ello. El ejemplo es de la vida cotidiana, pero el valor del acto de habla de autorización es similar en los dos ejemplos propuestos de autorización implícita, sea, en un caso, institucional $y$, en otro, familiar.

\section{Conclusión}

Así pues, como conclusión, puedo afirmar que es factible y común encontrar un acto de habla indirecto, es decir, implícito, de autorización, sea una autorización institucional o de cualquier otro tipo, aunque, como ya dijimos, en el caso de los hechos institucionales, los hablantes se inclinan a requerir actos explícitos. En el caso concreto que nos ocupa, la sentencia analizada del Tribunal Superior de Justicia de la Comunidad Valenciana, considero que el Tribunal no ha interpretado adecuadamente las normas de funcionamiento de los artículos referidos utilizados como argumentación por parte del demandante y aceptados como fundamentos de derecho por parte del Tribunal, pues si bien no hay una autorización explícita por parte de las autoridades universitarias, no cabe duda de que tal autorización estaba dada, implícitamente, por las mismas. Es cierto que se trata de hechos institucionales, pero institucionalmente se conocían las estancias, institucionalmente se per- 
mitieron, e institucionalmente, si no hubieran estado permitidas ni autorizadas, se debieran haber denunciado por ausencia del puesto de trabajo, y nunca promovido, como sí se hizo al juntar la docencia en un cuatrimestre.

\section{Referencias bibliográficas}

Albaladejo García, M. (1989): Derecho civil, I, 1², Barcelona, Edisofer.

Albaladejo, M. y S. Díez Alebart (dirs.) (2001): Comentarios al Código Civil, tomo I, vol. I: Artículos 1 al 7 del Código Civil. Madrid, Edersa.

Alcaraz Varó, E. (2005): "La lingüística legal: el uso, el abuso y la manipulación del lenguaje jurídico". En Turell, M. T. (ed.) (2005), págs. 49-66.

Alcaraz Varó, E. y B. Hughes (2002): El español jurídico. Barcelona, Ariel.

Austin, J. L. (1982): Cómo hacer cosas con palabras. Barcelona, Paidós.

Bach, K. y R. M. Harnish (1979): Linguistic Communication and Speech Acts. Cambridge, The MIT Press.

Ballmer, T. y W. Brennenstuhl (1981): Speech Act Classification. Berlín, Springer.

Bosque, I. y V. Demonte (dirs.) (1999): Gramática descriptiva de la lengua española. Madrid, Espasa-Calpe.

Casalmiglia, H. y A. Tusón (1999): Análisis del discurso. Barcelona, Ariel.

Cifuentes Honrubia, J. L. (2006): "Los actos de habla", http://www.liceus.com/cgi-bin/aco/ len/temas.asp\#semantica.

Cifuentes Honrubia, J. L. (2007): “La significación”, http://www.liceus.com/cgi-bin/aco/len/ temas.asp\#semantica.

Cole, P. y J. Morgan (eds.): Syntax and Semantics, 3. Speech Acts. Nueva York, Academic Press.

Coulthard, M. (2005): "Algunas aplicaciones forenses de la lingüística descriptiva". En Turell, M. T. (ed.), págs. 249-273.

De Castro y Bravo, F. (1984): Derecho Civil de España, I. Madrid, Civitas.

Díez-Picazo, L. (1980): “La interpretación de la Ley”, Anuario de derecho civil, 23-4, págs. 711-738.

Escandell Vidal, M. V. (1996): Introducción a la pragmática. Barcelona, Ariel.

Garrido Medina, J. (1999): "Los actos de habla. Las oraciones imperativas". En Bosque, I. y V. Demonte (dirs.), págs. 3879-3928.

Habermas, J. (1987): Teoría de la acción comunicativa. Madrid, Taurus.

Haverkate, H. (1984): Speech Acts. Speakers and Hearers. Reference and Referential Strategies in Spanish. Amsterdam, John Benjamins.

Hernández Marín, R. L. (1989): Teoría General del Derecho y de la Ciencia Jurídica. Barcelona, PPU.

Horn, L. R. y G. Ward (eds.) (2004): The Handbook of Pragmatics. Oxford, Blackwell.

Kasher, A. (ed.) (1998): Pragmatics. Critical Concepts, II y IV. Londres y Nueva York, Routledge.

Lozano, J., Peña Marín, C. y G. Abril (1982): Análisis del discurso. Hacia una semiótica de la interacción textual. Madrid, Cátedra.

Mey, J. L. (eds.) (1998): Concise Encyclopedia of Pragmatics. Oxford, Elsevier.

Portolés Lázaro, J. (2004): Pragmática para hispanistas. Madrid, Síntesis. 
Récanati, F. (1981a): La transparencia y la enunciación. Introducción a la pragmática. Buenos Aires, Hachette.

Récanati, F. (1981b): Les énoncés performatifs. París, Minuit.

Sadock, J. (2004): “Speech Acts”. En Horn, L. R. y G. Ward (eds.), págs. 53-73.

Salvador Coderch, P. (2001): “Aplicación de las normas jurídicas”. En Albaladejo, M. y S. Díez Alebart (dirs.), págs. 515-531.

Searle, J. (1979): Expression and Meaning. Studies in the Theory of Speech Acts. Cambridge, Cambridge University Press.

Searle, J. (1980): Actos de habla. Madrid, Cátedra.

Searle, J. (1992): Intencionalidad. Un ensayo en la filosofía de la mente. Madrid, Tecnos.

Searle, J. y V. Vanderveken (1985): Foundations of Illocutionary Logic. Cambridge, Cambridge University Press.

Turell, T. (ed.) (2005): Lingüística forense, lengua y derecho. Conceptos, métodos y aplicaciones. Barcelona, Universidad Pompeu Fabra.

Vanderveken, D. (1991): Meaning and Speech Acts. Cambridge, Cambridge University Press.

Vendler, Z. (1972): Res Cogitans. Nueva York, Cornell University Press.

Wierzbicka, A. (1987): English Speech Act Verbs. Sydney, Academic Press.

Wittgenstein, L. (1988): Investigaciones filosóficas. Barcelona, Crítica. 
